University of Nebraska - Lincoln

DigitalCommons@University of Nebraska - Lincoln

3-23-2005

\title{
Trichinella britovi etiological agent of sylvatic trichinellosis in the Republic of Guinea (West Africa) and a re-evaluation of geographical distribution for encapsulated species in Africa
}

\author{
E. Pozio \\ P. Pagani \\ G. Marucci \\ D.S. Zarlenga \\ E.P. Hoberg
}

See next page for additional authors

Follow this and additional works at: https://digitalcommons.unl.edu/usdaarsfacpub

This Article is brought to you for free and open access by the U.S. Department of Agriculture: Agricultural Research Service, Lincoln, Nebraska at DigitalCommons@University of Nebraska - Lincoln. It has been accepted for inclusion in Publications from USDA-ARS / UNL Faculty by an authorized administrator of DigitalCommons@University of Nebraska - Lincoln. 
Authors

E. Pozio, P. Pagani, G. Marucci, D.S. Zarlenga, E.P. Hoberg, D. De Meneghi, G. La Rosa, and L. Rossi 


\title{
Trichinella britovi etiological agent of sylvatic trichinellosis in the Republic of Guinea (West Africa) and a re-evaluation of geographical distribution for encapsulated species in Africa
}

\author{
E. Pozio ${ }^{\mathrm{a}, *}$, P. Pagani ${ }^{\mathrm{b}}$, G. Marucci ${ }^{\mathrm{a}}$, D.S. Zarlenga ${ }^{\mathrm{c}}$, E.P. Hoberg ${ }^{\mathrm{d}}$, \\ D. De Meneghi ${ }^{\mathrm{e}}$, G. La Rosa ${ }^{\mathrm{a}}$, L. Rossi $^{\mathrm{e}}$ \\ ${ }^{a}$ Department of Infectious, Parasitic and Immunomediated Diseases, Istituto Superiore di Sanità, viale Regina Elena 299, 00161 Rome, Italy \\ ${ }^{\mathrm{b}}$ Veterinaires Sans Frontieres, 14 Av.Berthelot, 69361 Lyon, Cedex 07 France \\ ${ }^{\mathrm{c}}$ Bovine Functional Genomics Laboratory and Animal Parasitic Diseases Laboratory, BARC East No. 1180, \\ 10300 Baltimore Avenue, Beltsville, MD 20705, USA \\ ${ }^{\mathrm{d}}$ US National Parasite Collection and Animal Parasitic Disease Laboratory, USDA, Agricultural Research Service, \\ BARC East No. 1180, 10300 Baltimore Avenue, Beltsville, MD 20705, USA \\ ${ }^{\mathrm{e}}$ Department of Animal Productions, Epidemiology and Ecology, University of Turin, via Leonardo da Vinci 44, 10095 Grugliasco, Italy
}

Received 9 February 2005; received in revised form 23 March 2005; accepted 23 March 2005

\begin{abstract}
In West Africa, Trichinella infection was documented in humans and animals from Senegal in the 1960s, and the biological characters of one isolate showed a lower infectivity to domestic pigs and rodents when compared with that of a Trichinella spiralis pig isolate from Europe. To identify the Trichinella species present in West Africa, a survey was conducted in a total of 160 wild animals in the Republic of Guinea. Three Viverridae, one true civet (Viverra civetta) and two African palm civets (Nandinia binotata) from the Fouta Djallon Massif, Pilimini Subprefecture, were found positive by artificial digestion of muscle samples. Trichinella larvae from these three viverrids were identified as Trichinella britovi and no difference was detected in three examined sequences from these African isolates and the reference strain of T. britovi from Europe, indicating common ancestry, an historically continuous geographic distribution, and recent isolation for African and European populations. The detection of T. britovi in West Africa modifies our knowledge about the distribution of encapsulated species of Trichinella in Africa. Thus, Trichinella nelsoni is now considered to have a distribution limited to the Eastern part of the Afrotropical region from Kenya to South Africa. This provides a plausible explanation for the presence of Trichinella T8 in Namibia and South Africa, and further suggests that T. britovi could be the Trichinella species circulating among wild animals of Northern Africa. (C) 2005 Australian Society for Parasitology Inc. Published by Elsevier Ltd. All rights reserved.
\end{abstract}

Keywords: Trichinella britovi; Trichinella T8; Trichinella nelsoni; West Africa; Republic of Guinea; Viverridae; Encapsulated species

\section{Introduction}

In Africa, trichinellosis is considered a rare human disease because of the practice of eating only well-cooked meats and because religious laws of most African populations forbid the consumption of pork, the most important source of infection worldwide. This accounted for

\footnotetext{
* Corresponding author. Tel.: +3906 4990 2304; fax: +3906 4938 7065 .

E-mail address: pozio@iss.it (E. Pozio).
}

no more than 100 documented human infections on this continent (Pozio et al., 1994). Consequently, the number of surveys to characterise the prevalence of Trichinella in wildlife and domestic animals of Africa is limited. Furthermore, most investigations were carried out before the 1990s and therefore lacked the correct taxonomic identification of the Trichinella species detected. At present, the protected areas of Kenya, Tanzania and South Africa (Nelson, 1970; Sachs, 1970; Young and Whyte, 1975) are the only regions of Africa where consistent information on Trichinella infection in sylvatic animals has been collected 
(Pozio et al., 1997). Therein, the etiological agent has been identified as Trichinella nelsoni or Trichinella T8 and has been detected repeatedly in numerous carnivore species (Pozio et al., 1992b, 1994, 1997), whereas Trichinella britovi has not been detected in the Africa continent so far. In Senegal (West Africa) in the 1960s, following a human outbreak of trichinellosis that involved nine people who had consumed smoked or cured meat from a warthog (Gretillat et al., 1967), Trichinella was detected in a side-striped jackal (Canis adustus) and in warthogs (Phacochoerus aethiopicus). A Trichinella isolated from a warthog in Senegal showed only low infectivity for swine and rodents (Gretillat, 1971) suggesting the existence of Trichinella strains different from that commonly found in domestic pigs. Unfortunately, this strain was lost before it could be genotypically or biochemically identified.

The aim of the present work was to investigate the presence of Trichinella infection in wildlife of West Africa and to genetically identify the etiological agent. The results show that Trichinella is present in sylvatic carnivores of the Fouta Djallon mountain area of the Republic of Guinea. Furthermore, the identification of the etiological agent as $T$. britovi, substantially modifies our knowledge on the geographic distribution of encapsulated species in Africa.

\section{Materials and methods}

\subsection{Area of investigation and sample collection}

The area of investigation encompasses the northwest region of the Republic of Guinea, named 'Moyenne Guinée'. It is mainly characterised by the Fouta Djallon Massif with an average altitude of $1000 \mathrm{~m}$ reaching $1538 \mathrm{~m}$ above sea level on the Loura Mountain in the northern area (Fig. 1). The lowest average temperature is $10{ }^{\circ} \mathrm{C}$ in December, but can reach $0{ }^{\circ} \mathrm{C}$ during the night. Precipitation ranges from 1,000 to $2,100 \mathrm{~mm}$ per year. The human population density in the area ranges from 15 up to 3,000 inhabitants/square $\mathrm{km}$ according to the national census of 1996.

Of 160 animals examined, 158 were mammals belonging to the families Suidae (12), Canidae (5), Viverridae (126), Felidae (5), Galagonidae (2), Cercopithecidae (7) and Hominidae (1). Of the remaining two, one was a vulture and one was a monitor lizard (Table 1). These animals were collected from 16 subprefectures of six prefectures (Labé, Koubia, Mamou, Pita, Tougue and Dalaba) of the region Moyenne Guinée of Guinea, but most of them $(114,71.7 \%)$ originated from the subprefecture of Pilimini (Koubia Prefecture).

Tissue (about $50 \mathrm{~g}$ ) was collected from the anterior tibial muscle of animals killed by local hunters for food $(94 \%)$ or by cars $(6 \%)$ from November 2001 up to June 2003. An aliquot of about $2 \mathrm{~g}$ from each fresh muscle

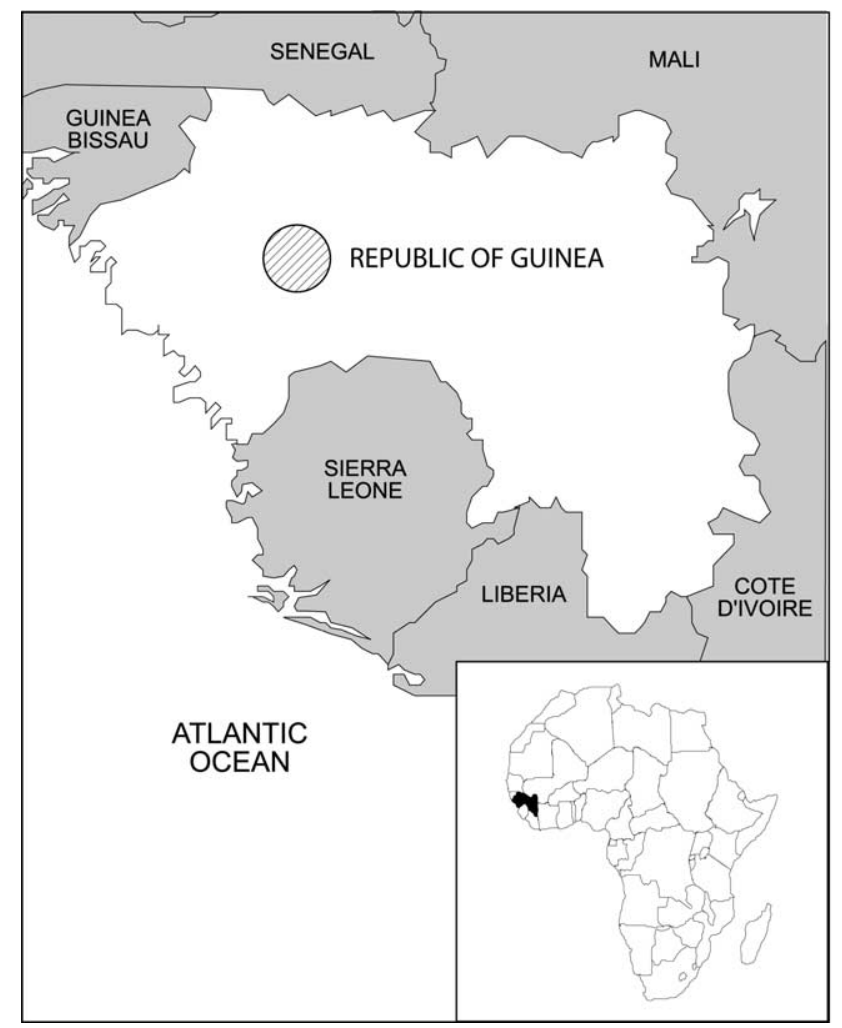

Fig. 1. Map of the Republic of Guinea in Western Africa. The circle shows the area of investigation named 'Moyenne Guinée', characterised by the presence of the Fouta Djallon Massif.

sample was first examined by trichinelloscopy (see below) within one day of the kill, whereas the remaining sample was preserved in a water solution with $1 \%$ merthiolate at room temperature.

Table 1

Animal species from Republic of Guinea examined for Trichinella

\begin{tabular}{ll}
\hline Host & Positive/examined (\%) \\
\hline Bush pig (Potamochoerus porcus) & $0 / 1$ \\
Warthog (Phacochoerus aethiopicus) & $0 / 10$ \\
Giant forest pig (Hylochoerus meinertzhageni) & $0 / 1$ \\
Side-striped jackal (Canis adustus) & $0 / 3$ \\
Golden jackal (Canis aureus) & $0 / 2$ \\
Pardine genet (Genetta pardina) & $0 / 15$ \\
False genet (Genetta thierryi) & $0 / 2$ \\
Genet (Genetta sp.) & $0 / 14$ \\
True civet (Viverra civetta) & $1 / 19(5.3)$ \\
African palm civet (Nandinia binotata) & $2 / 45(4.4)$ \\
African ichneumon (Herpestes ichneumon) & $0 / 1$ \\
Marsh mongoose (Atilax paludinosus) & $0 / 3$ \\
White-tailed mongoose (Ichneumia albicauda) & $0 / 27$ \\
Serval (Felis serval) & $0 / 1$ \\
Caracal (Felis caracal) & $0 / 3$ \\
African golden cat (Felis aurata) & $0 / 1$ \\
Night ape (Galago senegalensis) & $0 / 2$ \\
Green monkey (Chlorocebus aethiops) & $0 / 5$ \\
Patas monkey (Erythrocebus patas) & $0 / 2$ \\
Chimpanzee (Pan troglodytes) & $0 / 1$ \\
Monitor lizard (Varanus niloticus) & $0 / 1$ \\
Hooded vulture (Neophron monachus) & $0 / 1$ \\
\hline
\end{tabular}




\subsection{Isolation of the parasite}

At the end of the field study, samples preserved in merthiolate and a fresh sample from a Trichinella-positive animal preserved at $+4{ }^{\circ} \mathrm{C}$ were forwarded to the Faculty of Veterinary Medicine of the University of Turin, Italy, for laboratory investigations and larva isolation. Whole samples were separately digested by pepsin: $\mathrm{HCl}(1: 1 \%)$ in tap water at $39^{\circ} \mathrm{C}$ for $2 \mathrm{~h}$ (Gamble et al., 2000). Larvae were collected, washed, counted in triplicate and preserved in absolute ethyl alcohol for molecular studies. Larvae collected from the fresh muscles were also given per os to laboratory mice for the strain isolation and maintenance at the International Trichinella Reference Centre in Rome, Italy.

\subsection{Identification of larvae by molecular analyses}

Larva preparation followed the protocol proposed by Pozio and La Rosa (2003). Briefly, single larvae were washed 10 times in PBS, each larva was placed with $5 \mu \mathrm{L}$ of PBS in a $0.5 \mathrm{~mL}$ tube and store at $-20{ }^{\circ} \mathrm{C}$ until use. Then $2 \mu \mathrm{L}$ Tris- $\mathrm{HCl}(\mathrm{pH}$ 7.6) and 1 drop of sterile mineral oil were added. Each sample was heated at $90{ }^{\circ} \mathrm{C}$ for $10 \mathrm{~min}$ and then cooled on ice. Three micro litres of proteinase $\mathrm{K}$ solution (final concentration $100 \mu \mathrm{g} / \mathrm{mL}$ ) was added and incubated at $48^{\circ} \mathrm{C}$ for $3 \mathrm{~h}$. Samples were heated again at $90{ }^{\circ} \mathrm{C}$ for $10 \mathrm{~min}$ cooled on ice and then stored at $-20^{\circ} \mathrm{C}$ until use. Multiplex PCR analysis (Zarlenga et al., 1999; Pozio and La Rosa, 2003) was used to identify the species of the larvae collected from each host. PCR was performed using ExTaq DNA polymerase (Takara) in $50 \mu$ containing $1.5 \mathrm{mM} \mathrm{MgCl} 2,200 \mathrm{mM}$ dNTPs, 50 pmol of each primer and 0.5 unit of ExTaq DNA polymerase. The genes encoding the cytochrome oxidase subunit I ( $C O$ I) (Nagano et al., 1999), the mitochondrial large subunit ribosomalDNA (mt-lsrDNA) (La Rosa et al., 2001), and the region within the lsrDNA, known as the expansion segment $\mathrm{V}$ (ESV) (Zarlenga and Dame, 1992; Zarlenga et al., 1996), were analysed as molecular markers. Amplification products from the $C O I$, mt-lsrRNA and $E S V$ were obtained from single muscle larvae.

Since, it is not possible to distinguish Trichinella T8 from $T$. britovi by the multiplex-PCR analysis, a $21 \mathrm{bp}$ deletion in the internal transcribe space 2 (ITS2) sequence of Trichinella T8 in comparison with the same sequence of T. britovi has been used to distinguish between these two taxonomic entities by a PCR analysis. The primer set ITS2Gf (CCGGTGAGCGTAATAAAG) and ITS2Gr (TACACACAACGCAACGAT) (each $5^{\prime}$ to $3^{\prime}$ ) was designed to amplify the target sequence. The amplification was carried out for 35 cycles as follows: $94{ }^{\circ} \mathrm{C}$ for $30 \mathrm{~s}$, $51{ }^{\circ} \mathrm{C}$ for $1 \mathrm{~min}, 72{ }^{\circ} \mathrm{C}$ for $1 \mathrm{~min}$. The primer pair amplifies a fragment of $125 \mathrm{bp}$ in length for $T$. britovi and a fragment of 104 bp for Trichinella T8.

Muscle larvae of the following encapsulated and nonencapsulated reference strains were used as controls:
T. spiralis (code ISS3), Trichinella nativa (code ISS10), T. britovi (code ISS2) and its related genotype Trichinella T8 (code ISS124), Trichinella murrelli (code ISS35), $T$. nelsoni (code ISS37), Trichinella pseudospiralis (code ISS13), and Trichinella zimbabwensis (code ISS1029) (Pozio et al., 2001).

\subsection{Sequencing and analysis}

PCR products were gel-purified and sequenced using primer sets oTsr1/oTsr4, L6625/H7005, and P753/P754. The products of two independent amplification tubes were completely sequenced in both directions to confirm the nucleotide sequences. All sequences were aligned using the Clustal W program from OMIGA 2.0 (Accelrys). Final alignment of the $E S V$ sequences was performed manually to compare microsatellites.

\subsection{Cross-breeding}

Muscle larvae were separated into different sexes. Ten mice (CD1 females of $25 \mathrm{~g}$ ) were inoculated per os with one male and one female muscle larvae belonging to different isolates crossed in both directions, i.e. male of the Guinea isolate (code ISS1532) by the female of T. britovi (code ISS02) or Trichinella T8 (code ISS124) reference strains and male of the two reference strains by the female of the Guinea isolate. This was performed using a stomach tube connected to a syringe. Five mice were infected with a single male and female muscle larvae belonging to the same species/genotype as a control. To ensure that no larvae remained in the syringe or in the tube, both were rinsed twice with water, which was then examined under an inverted microscope. To improve the probability of producing offspring, all mice were immunosuppressed with $4 \mathrm{mg}$ of cyclophosphamide at 0,4 , and 8 days p.i. All mice were killed 40 days p.i., and the entire skinned and eviscerated carcase of each mouse was digested individually. Animals were housed and treated according to the European directive 8/609 EEC.

\section{Results}

Trichinella larvae were detected in three carnivores (1.9\% of carnivore mammals examined) belonging to two species of the family Viverridae (Table 1). The three positive animals originated from an area about $900 \mathrm{~m}$ above sea level $\left(12^{\circ} 07^{\prime}\right.$ longitude; $11^{\circ} 39^{\prime}$ latitude) from the Pilimini Subprefecture, near the border with the subprefecture of Matakaou (Koubia Prefecture). In the anterior tibial muscle of two African palm civets, two and three larvae/g were collected after artificial digestion (isolate codes ISS1533 and ISS1534), whereas 10 larvae/g were collected from the anterior tibial muscle of a true civet (isolate code ISS1532). 


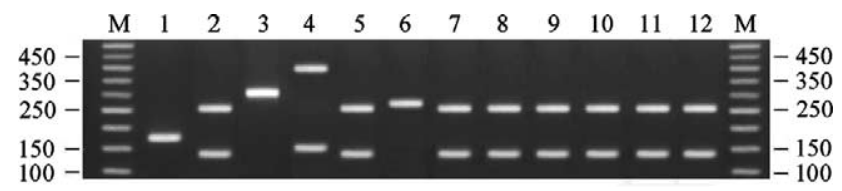

Fig. 2. Multiplex PCR analysis of single larvae of Trichinella from reference isolates and from the three positive animals detected in the Republic of Guinea. Lane 1, Trichinella spiralis reference strain (code ISS03); lane 2, Trichinella britovi reference strain (code ISS02); lane 3, Trichinella pseudospiralis reference strain (code ISS13); lane 4, Trichinella nelsoni reference strain (code ISS29); lane 5, Trichinella T8 reference strain (code ISS124); lane 6, Trichinella zimbabwensis reference strain (code ISS1029); lanes 7 and 8, larvae from a true civet (code ISS1532); lanes 9-12, larvae from two African palm civets (codes ISS1533 and ISS1534); M, molecular marker.

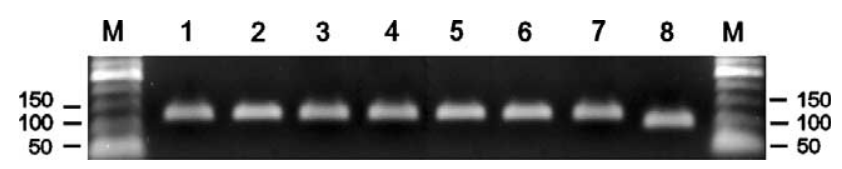

Fig. 3. PCR analysis of ITS2 sequence of single larvae of Trichinella from the three positive animals detected in the Republic of Guinea and from reference isolates. Lanes 1 and 2, larvae from a true civet (code ISS1532); lanes 3-6, larvae from two African palm civets (codes ISS1533 and ISS1534); and lane 7, Trichinella britovi reference isolate (code ISS02); lane 8, Trichinella T8 reference isolate (code ISS124); M, molecular marker.

The multiplex-PCR analysis of single muscle larvae from the three positive animals showed a pattern identical to that of the T. britovi reference strain from Europe (Fig. 2). The results of the second PCR analysis carried out to distinguish between T. britovi and Trichinella T8, confirmed that all larvae belong to T. britovi (Fig. 3). No differences were observed in the ESV, CO I, and $m t-l s r D N A$ sequences between Trichinella larvae from Guinea and those from the T. britovi reference strain from Europe (data not shown).

Single male and female adult worms of the isolate from Guinea (ISS1532) crossed with single male and female adults of the T. britovi and Trichinella $\mathrm{T} 8$ reference strains in both directions (data not shown).

\section{Discussion}

T. britovi is a species known to infect sylvatic carnivores of the Palearctic region from the Iberian Peninsula eastward across Eurasia to Japan (Pozio, 2001), including Turkey (Guruz, A.Y., 2004. The world's largest $T$. britovi outbreak in Izmir, Turkey. IX European Multicolloquium of Parasitology, 18-23 July, Valencia, Spain, abstract E-679) and Iran (Shaikenov and Boev, 1983). The presence of Trichinella T8 in Namibia and South Africa, a genotype strictly related to $T$. britovi, was tentatively explained as a passive introduction from Europe during the European colonisation (La Rosa and Pozio, 2000). T. nelsoni has always been considered the characteristic encapsulated species infecting sylvatic carnivores of Africa south of the Sahara (Murrell et al., 2000). This resulted from the identification of a Trichinella isolate from Kenya (identified as $T$. nelsoni) that demonstrated low infectivity in experimentally infected pigs and rats (Nelson, 1970) and an anecdotal correlation between this and the Trichinella strain from Senegal studied by Gretillat (Gretillat, 1971).

The finding of $T$. britovi in sylvatic carnivores of West Africa at a latitude of about $12^{\circ} \mathrm{N}$ required that we re-evaluate the distribution of encapsulated species on the African continent. Carnivore mammals are believed to have colonised the African continent following the formation of the land bridge between Africa and the Palearctic region, which occurred several times during the Oligocene and Miocene, i.e. between 30 and 17 million years ago (Savage, 1978; Briggs, 1995; Reader, 1998). We can speculate that the encapsulated taxa detected in Africa thus far (excluding T. spiralis, which has been introduced by humans in Egypt) have reached this continent at different times since the Miocene, consistent with varying periods for range expansion and geographic colonization by carnivores originating in Europe and Eurasia (Savage, 1978; Kingdon, 1997). T. nelsoni, among the most divergent of the encapsulating species (La Rosa et al., 2003; Gasser et al., 2004) may represent an indicator of early colonization and establishment in the African fauna. Secondarily, biotic expansion and subsequent isolation during the later Neogene may account for the occurrence of $T$. britovi and Trichinella T8. Significantly, Trichinella T8 retains the capacity to interbreed with $T$. britovi, but differs from this species based on several biochemical and molecular markers (La Rosa et al., 1992; Nagano et al., 1999). Successive isolation events due to the presence of important bio-geographical barriers such as the vast Zaire lake basin and the river Cross in Eastern Nigeria (Kingdon, 1990, 1997) and the changing environmental conditions (e.g. the development of the tropical forest) (Reader, 1998), may have prevented gene flow between populations of Trichinella present in carnivores living in Southern Africa from those living north and north-west of the equator, driving the speciation of $T$. britovi and Trichinella T8. Such an hypothesis requires examination in the context of phylogenetic analyses among Trichinella species.

The inability to identify discernable molecular markers separating isolates of $T$. britovi from Guinea and those from the Palearctic region, suggests common ancestry, continuity in distribution and very recent isolation between these two populations; alternatively this may also suggest the existence of substantial gene flow through the Quaternary. A mechanism for separation between populations of T. britovi in Northern Africa from those of Guinea is desertification of the Sahara region, which occurred about 2.0-2.5 million years ago (Potts and Behrensmeyer, 1992). Gene flow could have continued during expansion of the deserts along the West coast of Africa where the climate is still favourable for the survival of carnivores such as genets 
(Genetta genetta), jackals (Canis aureus), foxes (Vulpes rueppelli), caracals (Caracal caracal), African wild cats (Felis silvestris), grey mangoose (Herpestes ichneumon), striped hyenas (Hyaena hyaena), ratels (Mellivora capensis), and North African striped weasels (Ictonyx libyca) (Boitani et al., 1999), all of which could host this parasite.

In Northern Africa, encapsulated Trichinella larvae have been detected in sylvatic carnivores ( $G$. genetta, C. aureus and $H$. ichneumon) from Tunisia (Fassbender and Mayer, 1974) and in two wolves (Ahmed et al., 1985) from an unknown region of Egypt. Since, in Egypt, wolves are present only in the Sinai peninsula, we can argue that this was the area of origin of examined animals (Ferguson, 1981). Trichinellosis has also been documented in humans of Algeria (38 cases), who acquired the parasite from meat of wild boar (Sus scrofa) (Gérard, 1946; Lanoire et al., 1963; Verdaguer et al., 1963; Mémin et al., 1968; Barabe et al., 1977; Michel et al., 1986). Due to the Muslim religion, no pig production occurs in the Maghrebian region with the only exception being Egypt where domestic pigs are raised for consumption by tourists; and $T$. spiralis has been documented in pigs, dogs and synanthropic rats (La Rosa et al., 1992; Mikhail et al., 1994; Pozio, 1991; Therizol

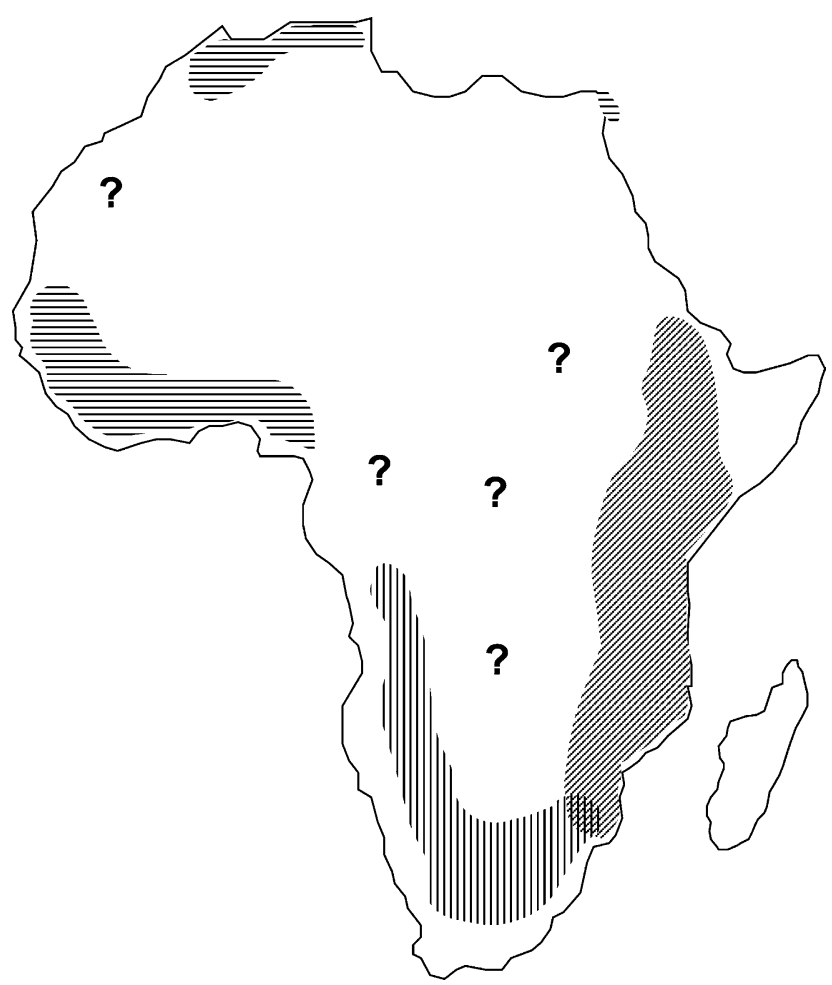

Fig. 4. Possible distribution area of encapsulated species of Trichinella in Africa. Trichinella nelsoni distribution area (diagonal lines); Trichinella britovi distribution area (horizontal lines); and Trichinella T8 distribution area (vertical lines). The overlapping area between $T$. nelsoni and Trichinella T8 corresponds to the Kruger National Park in which both genotypes have been detected in wildlife. Question marks show African regions for which information on Trichinella species are lacking, but the parasite could be present in wildlife. et al., 1975). Consequently, we suggest that $T$. britovi is the etiological agent of Trichinella infections occurring in wildlife across Northern Africa. The infection in Egypt detected by Ahmed et al. (1985) could have been T. britovi as well, because similar to T. britovi, and contrary to what occurs in T. spiralis (Pozio et al., 1992a), larvae from these wolves showed delayed development of the collagen capsule in muscles of experimentally infected rats.

On the basis of the present results and previously published data, we can now recognise a relatively restricted geographic distribution for T. nelsoni in the Eastern part of the Afrotropical region from Kenya to South Africa. The distribution of $T$. britovi appears to be greater than that considered in the past and now is shown to encompass Eurasia and the western areas of the Afrotropical region (Fig. 4). In addition, these results may explain the presence of Trichinella T8 in Namibia and South Africa, with populations of this genotype representing a geographic isolate or potential subspecies of T. britovi. The occurrence of several species of Trichinella in Africa appears related to independent episodes of biotic expansion by carnivores and their parasites from Europe and Eurasia during the Neogene including routes involving the Iberian Peninsula and Gibraltar or via the Arabian Peninsula. The timing and duration of such events that were initiated in the Miocene remain to be completely elucidated.

\section{Acknowledgements}

We are grateful to Marco Amati and Daniele Tonanzi for their excellent technical support. We are also indebted to Jean Dupouy-Camet to supply us data on human trichinellosis in Algeria. This work was supported by Research Project entitled 'Zoonosi trasmesse da alimenti: metodiche innovative per lo studio in ambito medico e veterinario' of the Italian Ministry of Health, No. 3AAF.

\section{References}

Ahmed, B.A., Fayek, S.A., Amer, O.H., 1985. Trichinellosis in wild wolves (Canis lupus) and experimental transmission to white rats (Rattus rattus albinus). Vet. Med. J. 33, 89-94.

Barabe, P., Motte, M., Larbi, M., Thomas, D., Bobin, P., Foullon, X., 1977. La trichinose aiguë, à propos de deux observations algériennes. Médecine et armées 5, 37-40.

Boitani, L., Corsi, F., De Biase, A., D’Inzillo Carranza, I., Ravagli, M., Reggiani, G., Sinibaldi, I., Trapanese, P., 1999. A Databank for the Conservation and Management of the African Mammals. Istituto di Ecologia Applicata, Rome, Italy.

Briggs, J.C., 1995. Global Biogeography. Developments in Paleontology and Stratigraphy, vol. 14. Elsevier, Amsterdam.

Fassbender, C.P., Mayer, P., 1974. Uber die Verteilung von Trichinella spiralis in der Muschulatur einiger nordafrikanischer Carnivoren. Deutsche Tierarztliche Wochenschrift 81, 284-287. 
Ferguson, W.W., 1981. The systematic position of Canis aureus and the occurrence of Canis lupus in North Africa, Egypt and Sinai. Mammalia 45, 459-465.

Gamble, H.R., Bessonov, A.S., Cuperlovic, K., Gajadhar, A.A., van Knapen, F., Noeckler, K., Schenone, H., Zhu, X., 2000. International Commission on Trichinellosis: recommendations on methods for the control of Trichinella in domestic and wild animals intended for human consumption. Vet. Parasitol. 93, 393-408.

Gasser, R.B., Hu, M., Abs, EL-Osta, Zarlenga, D.S., Pozio, E., 2004. Nonisotopic single-strand conformation polymorphism analysis of sequence variability in ribosomal DNA expansion segments within the genus Trichinella (Nematoda: Adenophorea). Electrophoresis 25, 3357-3364.

Gérard, R., 1946. Petite épidémie de trichinose en Algérie. Revue de Médecine Navale 1, 355-362.

Gretillat, S., 1971. Contribution a l'etude des variations d'adaptation et d'ubiquite de la souche ouest-africaine de Trichinella spiralis. Bull. W.H.O. 45, 520-524.

Gretillat, S., Vassiliades, G., 1967. Presence of Trichinella spiralis (Owen, 1835 ) in wild carnivora and swine of the region of the Senegal river basin. C.R. Acad. Sci. Hebd. Seances 264, 1297-1300.

Kingdon, J., 1990. Island Africa. Collins, London.

Kingdon, J., 1997. The Kingdon Field Guide to African Mammals. Academic Press, San Diego.

Lanoire, Duchier, Friez, 1963. Onze observations de trichinose en Algérie. Gaz. Hop. Paris 135, 305-310.

La Rosa, G., Pozio, E., 2000. Molecular investigation of African isolates of Trichinella reveals genetic polymorphism in Trichinella nelsoni. Int. J. Parasitol. 30, 663-667.

La Rosa, G., Pozio, E., Rossi, P., Murrell, K.D., 1992. Allozyme analysis of Trichinella isolates from various host species and geographic regions. J. Parasitol. 78, 641-646.

La Rosa, G., Marucci, G., Zarlenga, D.S., Pozio, E., 2001. Trichinella pseudospiralis populations of the Palearctic region and their relationship with populations of the Nearctic and Australian regions. Int. J. Parasitol. 31, 297-305.

La Rosa, G., Marucci, G., Zarlenga, D.S., Casulli, A., Zarnke, R.L., Pozio, E., 2003. Molecular identification of natural hybrids between Trichinella nativa and Trichinella T6 provides evidence of gene flow and ongoing genetic divergence. Int. J. Parasitol. 33, 209-216.

Mémin, Y., Pernod, J., Papillaud, J., Morelle, M., 1968. Aspects actuels du diagnostic et du traitement de la trichinose humaine (a propos d'une observation récente recueillie en France). Société Médicale Hôpitaux Paris 119, 113-123.

Michel, P., Zurlinden, A., Charvilla, L., Levencq, P., Janin, G., Bayle, A., Mojon, M., 1986. Cinq nouveaux cas de trichinose. Presse Médicale 15, 2073-2074.

Mikhail, E.M., Mansour, N.S., Awadalla, H.N., 1994. Identification of Trichinella isolates from naturally infected stray dogs in Egypt. J. Parasitol. 80, 151-154.

Murrell, K.D., Lichtenfels, R.J., Zarlenga, D.S., Pozio, E., 2000. The systematics of the genus Trichinella with a key to species. Vet. Parasitol. 93, 293-307.

Nagano, I., Wu, Z., Matsuo, A., Pozio, E., Takahashi, Y., 1999. Identification of Trichinella genotypes by polymerase chain reactionrestriction fragment length polymorphism of mitochondrial cytochrome $c$ oxidase subunit I gene. Int. J. Parasitol. 29, 1113-1120.

Nelson, G.S., 1970. Trichinosis in Africa. In: Gould, S.E. (Ed.), Trichinosis in Man and Animals. C.C. Thomas publisher, Springfield, IL, pp. 473-492.
Potts, R., Behrensmeyer, A.K., 1992. Late Cenozoic terrestrial ecosystems. In: Behrensmeyer, A.K., Damuth, J.D., Di Michele, W.A., Potts, R., Sues, H.D., Wing, S.L. (Eds.), Evolutionary Paleoecology of Terrestrial Plants and Animals. University of Chicago Press, Chicago, IL, pp. 424 541.

Pozio, E., 1991. Current status of food-borne parasitic zoonoses in Mediterranean and African regions. Southeast Asian J. Trop. Med. Public Health 22S, 85-87.

Pozio, E., 2001. New patterns of Trichinella infections. Vet. Parasitol. 98 133-148.

Pozio, E., La Rosa, G., 2003. PCR-derived methods for the identification of Trichinella parasites from animal and human samples. Methods Mol. Biol. 216, 299-309.

Pozio, E., La Rosa, G., Rossi, P., Murrell, K.D., 1992a. Biological characterizations of Trichinella isolates from various host species and geographic regions. J. Parasitol. 78, 647-653.

Pozio, E., La Rosa, G., Murrell, K.D., Lichtenfels, J.R., 1992b. Taxonomic revision of the genus Trichinella. J. Parasitol. 78, 654-659.

Pozio, E., Verster, A., Braack, L., De Meneghi, D., La Rosa, G., 1994. Trichinellosis south of the Sahara. In: Campbell, C.W., Pozio, E., Bruschi, F. (Eds.), Trichinellosis. ISS Press, Rome Italy, pp. 527-532.

Pozio, E., De Meneghi, D., Roelke-Parker, M.E., La Rosa, G., 1997. Trichinella nelsoni in carnivores from the Serengeti ecosystem, Tanzania. J. Parasitol. 83, 1195-1198.

Pozio, E., La Rosa, G., D’Ancona, F., Amati, M., Mancini Barbieri, F., De Giacomo, M., 2001. Twelve years of activity of the International Trichinella Reference Centre. Parasite 8, S44-S46.

Reader, J., 1998. Africa-a biography of the continent. Penguin Group Ltd, London.

Sachs, R., 1970. Zur epidemiologie der trichinellose in Afrika. Zeitschrift fur Tropenmedizin und Parasitologie 20, 117-126.

Savage, R.J.G., 1978. Carnivora. In: Maglio, V.J., Cooke, H.B.S. (Eds.), Evolution of African Mammals. Harvard University Press, Cambridge, UK, pp. 249-267.

Shaikenov, B., Boev, S.N., 1983. Distribution of Trichinella species in the old world. Wiad. Parazytol. 29, 595-608.

Therizol, M., Levy, R., Coulbois, J., Brochard, C., Berque, A., Betourne, C., 1975. Trichinose aiguë. A propos de qulques cas récents importés d'Egypte. Bull. Soc. Path. Exot. 68, 407-415.

Verdaguer, S., Hiltenbrand, C., Dangoumau, J., Vaillant, J.P., 1963. A propos d'un cas de trichinose humaine. J. Méd. Bordeaux 11, 16871694.

Young, E., Whyte, I.J., 1975. Trichinosis (Trichinella spiralis infestations) in wild animals of the Kruger National Park. J. S. Afr. Vet. Assoc. 46, 233-234.

Zarlenga, D.S., Dame, J.B., 1992. The identification and characterization of a break within the large subunit ribosomal RNA of Trichinella spiralis: comparison of gap sequences within the genus. Mol. Biochem. Parasitol. 51, 281-290.

Zarlenga, D.S., Aschenbrenner, R.A., Lichtenfels, J.R., 1996. Variations in microsatellite sequences provide evidence for population differences and multiple ribosomal gene repeats within Trichinella pseudospiralis. J. Parasitol. 82, 534-538.

Zarlenga, D.S., Chute, M.B., Martin, A., Kapel, M.O., 1999. A single multiplex PCR for unequivocal differentiation of six distinct genotypes of Trichinella and three geographical genotypes of Trichinella pseudospiralis. Int. J. Parasitol. 29, 1859-1867. 